\title{
Metodologia da problematizaçáo no contexto das disciplinas práticas terapêuticas supervisionadas
}

\author{
Maria Luisa Gazabim Simóes Ballarin ${ }^{\mathrm{a}}$, Rosibeth del Carmen Muñoz Palm ${ }^{\mathrm{b}}$, \\ Fábio Bruno de Carvalho ${ }^{a}$, Rosé Colom Toldrác
}

\begin{abstract}
aDoutor (a) em Saúde Mental, Universidade Estadual de Campinas - Unicamp, Docente da Faculdade de Terapia Ocupacional do Centro de Ciências da Vida da Pontifícia Universidade Católica de Campinas - PUC-Campinas, Campinas, SP, Brasil

${ }^{b}$ Mestre em Saúde Coletiva, Universidade Estadual de Campinas - Unicamp, Docente do curso de Terapia Ocupacional da Universidade Federal do Paraná - UFPR, Curitiba, PR, Brasil

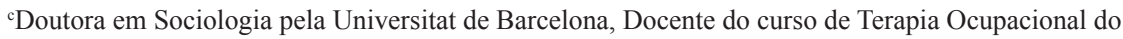
Departamento de Fisioterapia, Fonoaudiologia e Terapia Ocupacional - Faculdade de Medicina da Universidade de São Paulo - USP, São Paulo, SP, Brasil
\end{abstract}

\begin{abstract}
Resumo: A necessidade e a urgência em formar profissionais de saúde capazes de trabalhar em equipe, sob uma perspectiva interdisciplinar e humanista, concebendo a atuação com base na integralidade da atenção, vêm sendo amplamente debatidas. Nesse contexto, as metodologias ativas têm se mostrado relevantes, pois estimulam a capacidade crítica e a autonomia dos discentes. Assim, este trabalho tem por objetivo discorrer sobre a utilização de metodologia ativa, no caso a metodologia da problematização, no processo de ensino-aprendizagem de alunos do último ano da graduação da Faculdade de Terapia Ocupacional da Pontifícia Universidade Católica de CampinasSP - PUC-Campinas, considerando particularmente as disciplinas Práticas Terapêuticas Supervisionadas - PTS VI e VII. Para tanto, utilizou-se como instrumentos de coleta de dados registros das reuniões dos estágios, relatórios de avaliação das supervisões, projeto pedagógico do curso de Terapia Ocupacional e a experiência acumulada dos docentes que ministraram as referidas disciplinas, subsidiaram a análise dos dados. O processo vivenciado evidenciou que os dispositivos pedagógicos utilizados, ao apoiarem-se na metodologia da problematização, proporcionaram maior conscientização e responsabilização dos graduandos, além de maior autonomia e capacidade para planejar e elaborar procedimentos de intervenção exigidos, nos diferentes cenários de desenvolvimento das referidas disciplinas. Evidenciou, ainda, maior capacidade dos discentes para transformar as situações experimentadas em conhecimento, possibilitando a ampliação da perspectiva de tomada de decisões e a construção de uma atitude mais reflexiva. Todos esses aspectos asseguraram a vivência de um processo de ensino-aprendizagem contextualizado, que buscou englobar as dimensões pessoal, social, cognitiva, técnica e ética.
\end{abstract}

Palavras-chave: Terapia Ocupacional, Educação em Saúde, Aprendizagem Ativa.

\section{Problematization methodology in the context of supervised therapeutic practice disciplines}

\begin{abstract}
The urgent need to train professionals capable of working in teams from a humanist perspective, conceiving this action on the basis of comprehensiveness of care, has been widely debated. In this context, active methods of teaching and learning have proven to be relevant because they stimulate the critical capacity and autonomy of learners. In this experience report, we aimed to discuss the use of active methodology, in this case problem methodology, in the teaching-learning process of senior undergraduate students at the College of Occupational Therapy of the 'Pontifícia Universidade Católica de Campinas' - PUC-Campinas, São Paulo state, particularly considering the disciplines related to field practice and/or supervised therapeutic practice (STP). To
\end{abstract}

Autor para correspondência: Maria Luisa Gazabim Simões Ballarin, Pontifícia Universidade Católica de Campinas, Av. Jonh Boyd Dunlop, s/n, Jardim Ipaussurama, CEP 13060-904, Campinas, SP, Brasil, e-mail: mlballarin@ puc-campinas.edu.br

Recebido em 3/5/2011; $1^{\text {a }}$ Revisão em 29/8/2011; Aceito em 15/12/2011. 
this end, the following instruments were used for data collection: records of meetings of the evaluation stages, evaluation reports of supervision, the educational project of the Occupational Therapy course, and the experience of the teachers who taught those discipline. The analysis of the collected material, together with the reflections relevant to the experience of teachers showed that the strategies and devices used in the educational disciplines, by relying on problem methodology, resulted in greater awareness and accountability of students, as well as greater autonomy and capacity to plan and develop intervention procedures required under different development scenarios of those disciplines. Moreover, we also observed the capacity of students to transform the situations experienced into knowledge, enabling the expansion of the decision-making perspective and the construction of a more reflective attitude. All these aspects have ensured the existence of a teaching-learning perspective that sought to encompass personal, social, cognitive, technical and ethical dimensions.

Keywords: Occupational Therapy, Health Education, Active Learning.

\section{Introdução}

Durante muitos anos, o modelo disciplinar centrado na racionalidade biomédica, e restrito à dimensão biológica, serviu de base para a formação dos profissionais da saúde, incluindo os terapeutas ocupacionais. No entanto, esse modelo disciplinar não tem sido mais suficiente para responder às complexas demandas de saúde da população, bem como a de formação dos profissionais de saúde. O desafio atual imposto às instituiçôes de ensino superior traduz-se na urgência em formar um profissional capaz de trabalhar em equipe, numa perspectiva interdisciplinar, humanista e que conceba sua atuação com base na integralidade da atenção à saúde, conforme as diretrizes e princípios do Sistema Único de Saúde (SUS).

Para que a prática atenda à integralidade prevista pelo SUS, é preciso exercitar efetivamente o trabalho em equipe, desde o processo de formação do profissional (MACHADO et al., 2007) e, nesse contexto de aprendizagem, o aprender e o ensinar integram o cotidiano do trabalho de equipe e da própria organizaçáo do serviço (TOLDRÁ; PALM, 2009).

No que se refere à formação de terapeutas ocupacionais, constata-se que algumas iniciativas vêm sendo adotadas no sentido de implementar as diretrizes curriculares nos cursos de graduação, pautadas no paradigma da integralidade da atenção, no compromisso de formar profissionais críticos, capacitados a responder às demandas de saúde $\mathrm{e}$ socioculturais da população que assiste.

Segundo o COFFITO (CONSELHO..., 2010),

[...] a formação do terapeuta ocupacional deverá atender ao sistema de saúde vigente no país, a atenção integral da saúde no sistema regionalizado e hierarquizado de referência e contrarreferência e o trabalho em equipe.
Contudo, a formação diferenciada dos profissionais de saúde requer profundas mudanças na prática pedagógica, e isso implica, segundo Feuerwerker e Sena (2002), na adoçấo de um novo referencial teórico-metodológico. Outro aspecto relevante no campo de formação de profissionais em saúde relaciona-se à inserção na prática profissional e, consequentemente, aos estágios curriculares. Estes devem caracterizar-se como eixos norteadores dos currículos, já que são espaços ricos para o enfrentamento de problemas e situaçóes que exigem conhecimento técnico, postura ética, parcerias com a comunidade e os serviços.

No âmbito da formação de terapeutas ocupacionais, as disciplinas relacionadas às práticas de campo ou práticas terapêuticas supervisionadas (PTS) são componentes curriculares obrigatórios, cujo processo de ensino-aprendizagem está pautado na experiência do exercício profissional em diversos campos. Assim, considerando os aspectos descritos, este trabalho tem por objetivo discorrer sobre a experiência de utilização da problematizaçáo, entendida aqui como metodologia ativa de ensinoaprendizagem e o papel do docente-supervisor na formação de terapeutas ocupacionais, no contexto das disciplinas PTS VI e VII, oferecidas para discentes do último ano de graduação da Faculdade de Terapia Ocupacional da Pontifícia Universidade Católica de Campinas - PUC-Campinas. Antes, porém, faz-se necessário tecermos algumas consideraçóes sobre os referenciais teórico-metodológicos das práticas pedagógicas ditas inovadoras, no caso as metodologias ativas.

\section{As metodologias ativas de ensino-aprendizagem}

A necessidade de rompimento com o modelo de formação tradicional que há décadas vem sendo 
utilizado para formar profissionais na área da saúde, com vistas à construçấo de um perfil mais adequado para atuar no Sistema Único de Saúde, explica a amplitude que ganharam as discussóes relacionadas ao emprego das metodologias ativas de ensinoaprendizagem nesse campo.

De acordo com Batista et al. (2005), prioritariamente duas propostas de metodologias ativas vêm sendo mais utilizadas no Brasil. Estas podem ser identificadas na dimensão problematizadora do processo ensino-aprendizagem, quais sejam, aprendizagem baseada em problemas (ABP) e pedagogia da problematização, esta última foco deste trabalho. Ambas caracterizam-se como metodologias ativas e baseiam-se no desenvolvimento do processo de ensino-aprendizagem a partir de experiências reais e/ou simuladas, onde se busca solucionar os problemas que emergem da experiência por meio de um processo de ação-reflexão-ação. Os grupos de reflexão e o método Balint também são descritos na literatura especializada como metodologias ativas (GUANAES; MATTOS, 2008; ABREU, 2009). Apesar das semelhanças e dos pontos convergentes existentes entre essas metodologias, Abreu (2009) enfatiza algumas diferenças, tais como: base teórica, estruturação metodológica e etapas do processo de ensino-aprendizagem. No que se refere às bases teóricas pertinentes à $\mathrm{ABP}$, pode-se dizer que estas dialogam com as proposiçóes educativas formuladas por John Dewey e, portanto, são centradas no cognitivismo. A metodologia da problematização baseia-se na concepção histórico-crítica da educação, sendo que o trabalho pedagógico se inspira no materialismo histórico dialético e encontra fundamentos principalmente na filosofia da práxis e na pedagogia libertadora/ problematizadora (PENAFORTE, 2001; FREIRE, 2007; MARIN et al., 2010). Já o método Balint apoia-se teoricamente nos constructos da Psicanálise e guarda semelhança com a prática reflexiva proposta por Balint e, de acordo com Guanaes e Mattos (2008), difere no modo de manejar o processo de aprendizagem grupal.

Do ponto de vista da estruturação e etapas do processo, segundo Komatsu (2003), na ABP os problemas trabalhados pelos estudantes são elaborados pelos professores/tutores, conforme sequência proposta no currículo em sete etapas, enquanto na metodologia da problematização os problemas são elaborados pelos estudantes com base na exploração da realidade social e processados em cinco etapas. No método Balint, os problemas também são processados em cinco etapas, sendo o foco central do trabalho dirigido aos aspectos subjetivos dos sujeitos envolvidos. Embora seja relevante considerarmos as diferenças existentes entre as metodologias ativas, é correto afirmar que para operarem de modo construtivo e estimularem o pensamento crítico e a autonomia dos graduandos é necessário que o docente que as emprega assuma uma nova postura, ou seja, de coparticipação no processo de ensino-aprendizagem. Assim, o ensinar é um ato que exigirá respeito à autonomia de cada sujeito envolvido no processo, além de reconhecimento mútuo (MITRE et al., 2008).

\section{Fundamentação teórico e prática da metodologia da problematização}

Como descrito antes, especificamente em relação à metodologia da problematização, objeto deste estudo, Bordenave e Pereira (1982), Berbel (1998, 1999, 2001) e Colombo e Berbel (2007) destacam que, embora seja um caminho rico do ponto de vista do ensino e da pesquisa, é também um caminho complexo que demanda esforços para que se alcancem os resultados esperados. Seu emprego, segundo Maguerez (1970), implica em percorrer uma trajetória que envolve cinco etapas. Tais etapas podem ser descritas a partir de um esquema denominado Arco de Maguerez e são elas:

- Observação da realidade - momento de se olhar atentamente a realidade, neste caso, estamos nos referindo aos cenários de práticas escritos no Quadro 1. Os estagiários eram orientados a buscar e identificar aquilo que emergia de forma mais contundente;

- Definição do problema - momento de se definir a questão a ser estudada, dos pontos-chave da problemática;

- Teorização - momento do estudo propriamente dito e da ampliaçáo dos referenciais teóricos;

- Hipóteses de solução - momento de construir novos saberes e açôes;

- Aplicação à realidade - momento de voltar ao cenário onde emergiu a problemática, objetivando transformá-la.

Para Freire (2004), um dos princípios teóricos mais significativos das metodologias ativas é a autonomia, a qual deve emergir no âmago da relação dialética existente entre docentes e discentes, no caso, supervisores ou docentes e/ou estagiários. Esses sujeitos devem se reconhecer mutuamente, aceitando suas diferenças, mas não se reduzindo à condiçâo de objeto um do outro. Nessa perspectiva, 
Quadro 1. Instituições e diferentes cenários de desenvolvimento das disciplinas PTS VI e VII.

\begin{tabular}{|c|l|l|c|}
\hline Docente & \multicolumn{1}{|c|}{ Instituição } & \multicolumn{1}{c|}{ Campo de atuação } & $\mathbf{N}^{\circ}$ de alunos \\
\hline 01 & $\begin{array}{l}\text { Centro de Atenção Psicossocial* e Núcleo de } \\
\text { Atendimento Clínico** }\end{array}$ & Saúde mental & 3 a 8 \\
\hline 02 & $\begin{array}{l}\text { Núcleo de Oficinas de Trabalho**e Núcleo de } \\
\text { Atendimento à Crise** }\end{array}$ & Saúde mental & 3 a 8 \\
\hline 03 & Hospital Universitário*** & Contexto hospitalar área física & 4 a 6 \\
\hline 04 & Ambulatório Adulto de Terapia Ocupacional*** & Reabilitação física & 4 a 6 \\
\hline
\end{tabular}

*Serviço vinculado à secretaria de saúde do município de Campinas-SP; **Unidades vinculadas ao Serviço de Saúde Dr. Cândido Ferreira; ***Serviços vinculados à Pontifícia Universidade Católica de Campinas.

[...] quanto mais se problematizam os educandos, como seres no mundo e com o mundo, tanto mais se sentirão desafiados. [...] desafiados, compreendem o desafio na própria ação de capacitá-los (FREIRE, 2007, p. 80).

Dito de outro modo, a educaçấo contemporânea deve pressupor um discente-estagiário capaz de autogerenciar seu processo de formaçáo e um docente-supervisor capaz de estimular e facilitar esse processo. Portanto, o ato de aprender deve estar apoiado num processo que permita o estabelecimento de diferentes tipos de relações entre fatos e objetos, desencadeando reconstruçóes e contribuindo para que o apreendido possa ser utilizado em diferentes situaçôes (DEMO, 2004; MITRE et al., 2008).

A implantação da metodologia da problematização no contexto das disciplinas PTS VI e VII exigiu compreender e incorporar a necessidade de enfatizar a constituição de um ambiente de trabalho dinâmico, acolhedor e estimulante, pautado no diálogo e nas relaçôes grupais.

\section{Contextualizando o funcionamento das disciplinas - PTS VI e VII}

As disciplinas PTS VI e VII são ministradas por docentes e oferecidas no primeiro e segundo semestres do último ano de graduação da Faculdade de Terapia Ocupacional da PUC-Campinas, portanto caracterizam-se como disciplinas semestrais.

Sua dinâmica de funcionamento consiste em dividir os alunos da classe em grupos que variam de quatro a oito estudantes, de acordo com a modulação. Tanto PTS VI como PTS VII contemplam uma carga horária de 18 horas semanais, sendo que 17 horas estão destinadas às atividades práticas em serviços intramuros ou extramuros à universidade e uma hora destinada aos encontros coletivos com todos os discentes da classe.
O relato que ora se apresenta envolveu o trabalho de quatro docentes da Faculdade de Terapia Ocupacional da PUC-Campinas, que ministraram as disciplinas PTS VI e VII em diferentes cenários e instituiçóes de estágio (Quadro 1) entre os anos de 2005 e 2008.

Nesses diferentes cenários de estágio, os quatro docentes-supervisores procuraram sistematicamente discutir e refletir sobre a utilização da problematização no contexto das supervisôes, não somente entre si, mas também com os profissionais das equipes técnicas dos serviços nos quais se inseriam os estagiários, possibilitando uma maior interação entre todos os envolvidos, dando-se assim ênfase ao trabalho coletivo e ao aprendizado. Além disso, trabalhou-se na perspectiva da aprendizagem significativa, buscando problematizar com objetividade as demandas emergentes trazidas pelos estagiários, favorecendo o aprender fazendo (CHIESA et al., 2007).

\section{A experiência dos docentes nos diferentes cenários de estágio das disciplinas}

Partindo do pressuposto de que a educação problematizadora trabalha a construção de conhecimentos a partir da vivência de experiências significativas de Cyrino e Toralles-Pereira (2004) e aproveitando o cenário de práticas, os quatro docentes envolvidos nas disciplinas PTS VI e VII passaram a planejar e articular as supervisóes do seu grupo de estagiários. Nesse processo de planejamento, ressaltamos que o eixo norteador do trabalho docente centrou-se no entendimento de que a aprendizagem significativa é aquela que envolve o estudante em sua totalidade. Desse modo, as ideias, sentimentos, cultura, valores e o conhecimento técnico dos estagiários foram sendo valorizados no seu conjunto. A partir de entáo estabeleceu-se um percurso sequencial que se iniciava com: 
- Apresentação das situaçóes-problema vivenciadas por cada um dos integrantes do grupo de estagiários;

- Seleção de uma das situações-problema trazidas na supervisão pelo grupo de estagiários;

- Problematização da situação-problema selecionada;

- Orientação e sistematização das fontes de pesquisa para análise da situação-problema;

- Elaboração de síntese teórica e prática mais aprofundada da situaçáo selecionada;

- Socialização dos aspectos discutidos;

- Avaliação do processo.

Buscamos a partir da sequência estabelecida que os estagiários pudessem refletir de modo mais detalhado sobre a realidade e/ou situação concreta apresentada, exercitando assim sua capacidade de reflexão. Após o fechamento de uma situação-problema, iniciava-se um novo ciclo. A especificidade e o enfoque norteador da supervisão, se pedagógica, clínica ou institucional, eram determinados pelas características e variáveis envolvidas na situação-problema.

A atribuição de planejamento dos docentes consistiu basicamente em selecionar as estratégias de aprendizagem mais adequadas à discussão de cada situação-problema. As estratégias utilizadas variaram de acordo com os grupos de estagiários e do supervisor, sendo que o estudo de caso foi o dispositivo pedagógico mais empregado para trabalhar as situaçōes-problema selecionadas. Segundo Galdeano, Rossi e Zago (2003) e Almeida e Souza (2005), o estudo de um caso permite que os estagiários observem, entendam, analisem e descrevam uma determinada situação real, adquirindo conhecimento e experiência que podem ser importantes na tomada de decisão. Não se trata apenas de uma descrição detalhada da história do paciente, do diagnóstico e das possíveis formas de tratamento. Além da coleta de informaçôes, o estudo de caso exige a construção de um processo de pensamento que viabiliza a identificação de categorias, a análise dos dados, a determinaçáo de açôes para soluçấo de problema e a avaliação.

Simulações de situações clínicas vivenciadas pelos estagiários também foram utilizadas como ferramentas para se efetivar as discussôes e o percurso sequencial planejado, conforme descrito anteriormente. Ressalta-se que essas estratégias foram gradualmente implementadas, na medida em que as demandas dos estagiários emergiam em decorrência do contato com os contextos dos serviços em que estavam inseridos, facilitando a construção do conhecimento no cotidiano do serviço, baseado na ação, reflexão crítica e ação.

Constatou-se que algumas temáticas eram recorrentes nas supervisōes, independentemente do serviço e área de atuação em que estavam inseridos, e refletiam situaçóes-problema relacionadas à dificuldade do estagiário em articular a teoria e a prática, deficiências teóricas e práticas em que se evidenciavam desajustes no manejo do processo terapêutico ocupacional. Assim, eram frequentes as discussóes que giravam em torno de questóes relativas ao emprego de instrumentos de avaliação mais adequados a determinado caso clínico, seleção de recursos e técnicas, elaboração de projetos terapêuticos, além de questôes relativas à formação pessoal (inseguranças, dificuldades inter-relacionais, medos), aspectos pertinentes à estrutura institucional e ao Sistema Único de Saúde (SUS). Entendemos que muitas das discussóes aqui descritas associam-se ao desafio de quem ainda está no início de sua atuação prática, no caso os estagiários. Carvalho et al. (1999) salientam que as vivências iniciais de estagiários nos cenários de práticas podem gerar tensóes e ansiedades, sentimentos que podem interferir negativamente no processo de ensinoaprendizagem. Todas essas questôes são relevantes e nos levam a refletir sobre as vicissitudes dos processos de ensino-aprendizagem de um iniciante. Entretanto, compreendemos que ao favorecerem um processo educativo centrado no estudante, na construção de espaços de diálogo, interação e reflexão, as metodologias ativas favorecem maior apropriação de conteúdos e possibilitam autonomia (FEUERWERKER, 2003; KODJAOGLANIAN, 2003; FAGUNDES; FRÓES BURNHAM, 2005).

Além disso, segundo Fagundes e Fróes Burnham (2005, p. 108), o que se aprende tem relação com o local, com o método de ensino, com a interação das pessoas e com o momento, pois

[...] o que define o sentido da formação profissional é, predominantemente, a relação que se estabelece nos espaços nos quais se materializa a educação (especificamente na área da saúde: sala de aula, laboratórios, serviços de saúde, espaços da comunidade).

Procuramos dar ênfase à constituição de um ambiente de supervisão acolhedor e estimulante, pautado no diálogo e nas relaçóes grupais, na medida em que

[...] a tarefa de formar e ensinar envolve uma delicada relação em que tanto os docentes como os estudantes aprendem. (TOLDRÁ; CARVALHO; BALLARIN, 2008, p. 135). 
Ao longo desse processo pudemos constatar também a importância de nosso papel como facilitador do processo ensino-aprendizagem dos estagiários, assim como o papel de integrador de conhecimentos e articulador do processo de avaliaçáo (MORAES; BARBEL, 2006).

Como integradores de conhecimentos, nosso trabalho dirigiu-se ao fornecimento de suporte teórico-prático complementar. Procuramos assim estabelecer maior interação com os demais docentes do curso e profissionais da equipe técnica que integravam as equipes dos serviços, de forma a incluir a pluralidade de saberes e práticas existentes no contexto de aprendizagem. Já em relação ao papel de facilitador do processo ensino-aprendizagem, destacamos a necessidade de funcionarmos como estimuladores da comunicação e da interação entre o grupo, criando formas mais participativas de convivência, abrindo espaços de expressão e levando em conta o processo e o ritmo de aprendizagem de cada estagiário.

Como articuladores do processo de avaliação, procuramos estar atentos ao caminho percorrido, entre o ponto de partida, no caso a bagagem que os estagiários traziam, no início do estágio, e o ponto em que objetivávamos atingir. Desse modo, além das avaliações das atividades decorrentes das intervenções clínicas e sociais efetivadas ao longo do processo, como avaliaçôes escritas, relatórios de atividades, apresentação de seminários, elaboração de trabalhos científicos, outros aspectos foram considerados para efetivar a avaliação final, tais como: o diálogo com os demais profissionais da equipe do serviço, o acompanhamento contínuo do desempenho dos estagiários e autoavaliação; afinal, para Mitre et al. (2008, p. 2.138),

[...] a avaliação deve ser um processo amplo, que provoque uma reflexáo crítica sobre a prática, no sentido de captar seus progressos, suas resistências, suas dificuldades e possibilitar deliberaçôes sobre as açôes seguintes.

Foi possível constatarmos, ao longo de todo o processo, uma evolução significativa dos grupos de estagiários, tanto no que se refere à aquisição de conhecimentos sobre o manejo do processo terapêutico ocupacional, como no que diz respeito à autonomia e à capacidade reflexiva diante das inúmeras situaçôes vivenciadas no cotidiano dos serviços. De outro modo, os questionamentos constantes dos estagiários, a necessidade de readequação dos diferentes dispositivos pedagógicos e o trabalho desenvolvido em parceria com os demais profissionais inseridos no contexto dos serviços em que desenvolvíamos nossas práticas também funcionaram como fatores que contribuíram para a constituição de um cenário interativo e de amadurecimento. Enfatizamos ainda que o processo de avaliação nos exigiu uma postura reflexiva, ativa e funcionou como estímulo à construção de uma educação menos fragmentada ligando o ensino teórico ao campo de trabalho e à atuação profissional, em uma perspectiva mais integrada e contextualizada.

\section{Sobre os desafios do processo vivenciado pelos docentes e estagiários}

A experiência descrita, pertinente ao processo ensino-aprendizagem, com o emprego da metodologia da problematizaçáo, implantado nas disciplinas PTS VI e VII, evidenciou aquisiçóes significativas, tanto em relação aos estagiários como aos docentessupervisores. Contribuiu ainda para a produção de projetos de intervenção por parte dos estagiários que, em nossa análise, qualificou as ações de saúde nos diferentes contextos de atenção. No entanto, também explicitou dificuldades e limitaçôes. Assim, há que se considerar a existência de lacunas que requerem rigorosa atenção. Nesse sentido, foi possível identificar alguns fatores que funcionaram como obstáculos, tais como: falta de integração entre os conteúdos teóricos correlatos de diferentes disciplinas que subsidiam as PTS VI e VII; fragilidades e deficiências na formação dos próprios docentes-supervisores com relação à vivência prática no emprego de metodologias ativas, dificuldades para delimitar um novo modo de funcionar como estudante, já que muitas vezes mostram-se acostumados com o modelo de ensino tradicional. Apesar do investimento efetivado pelos docentes-supervisores, tanto no que se refere à avaliação da própria experiência, como no que se relaciona aos espaços coletivos de discussão e reflexão, evidenciou-se a necessidade de se aprimorar as estratégias utilizadas, pois estas envolvem a incorporação de novos referenciais teórico-práticos da pedagogia da problematização. Além disso, evidenciou a urgência do desenvolvimento de investigaçóes sistematizadas sobre a utilização de metodologias ativas no âmbito da formação de terapeutas ocupacionais.

\section{Finalizando o relato da experiência}

A inserção da metodologia da problematização, uma metodologia ativa, nas disciplinas PTS VI e VII 
se caracterizou como uma experiência importante na formação de terapeutas ocupacionais, na medida em que tanto os docentes quanto os estagiários puderam refletir criticamente sobre os sentidos do ensinar e aprender, aproximar os conhecimentos da realidade dos serviços em que estavam inseridos, viabilizando assim processos de mudanças no campo de atuação. Possibilitou ainda a construçâo de espaços de diálogo, troca de informaçóes, relaçấo de cooperação e respeito entre todos os envolvidos. Todavia, a metodologia da problematização é um dos muitos métodos de ensino-aprendizagem que podem ser empregados no processo de formação do profissional de saúde.

Assim, apesar dos limites da experiência, entendemos que as instituiçôes formadoras de profissionais de saúde devem empenhar-se no sentido de mudarem suas práticas pedagógicas. Tais mudanças têm por finalidade formar profissionais qualificados, com capacidade de compreender e intervir de forma mais efetiva nas demandas da populaçáo que assistem e de modo a qualificar a assistência desenvolvida pelos serviços, o que, em nossa análise, favorece o reconhecimento da profissão tanto nos locais de estágios como junto aos demais profissionais da equipe técnica dos serviços e na comunidade.

\section{Referências}

ABREU, J. R. P. Contexto atual do ensino médico: Metodologias tradicionais e ativas necessidades pedagógicas dos professores e das estruturas das escolas. 2009. $105 \mathrm{f}$. Dissertação (Mestrado em Ciências da Saúde)-Faculdade de Medicina, Universidade Federal do Rio Grande do Sul, Porto Alegre, 2009.

ALMEIDA, A. P. S.; SOUZA, N. V. D. O. Estudo de caso: uma estratégia para construção de atitude crítico-reflexiva em discente de enfermagem. Revista Enfermagem UERJ, Rio de Janeiro, v. 13, n. 2, p. 204-209, 2005.

BATISTA, N. et al. O enfoque problematizador na formação de profissionais da saúde. Revista de Saúde Pública, São Paulo, v. 39, n. 2, p 231-237, 2005. http:// dx.doi.org/10.1590/S0034-89102005000200014

BERBEL, N. A. N. A problematização e a aprendizagem baseada em problemas: diferentes termos ou diferentes caminhos? Interface: Comunicação, Saúde, Educação, Botucatu, v. 2, p. 139-154, fev. 1998. http://dx.doi. org/10.1590/S1414-32831998000100008

BERBEL, N. A. N. A metodologia da problematização e os ensinamentos de Paulo Freire: uma relaçáo mais que perfeita. In: BERBEL, N. A. N. Metodologia da problematizaçâo: fundamentos e aplicaçôes. Londrina: Ed. UEL, 1999. p. 1-28.
BERBEL, N. A. N. (Org.). Avaliação da aprendizagem no ensino superior: um retrato em cinco dimensōes. Londrina: Ed. UEL, 2001.

BORDENAVE, J. D.; PEREIRA, A. M. Estratégias de ensino-aprendizagem. Petrópolis: Vozes, 1982.

CARVALHO, M. D. B. et al. Expectativas dos alunos de enfermagem frente ao primeiro estágio em hospital. Revista da Escola de Enfermagem da USP, São Paulo, v. 33, n. 2, p. 200-206, 1999.

CHIESA, A. M. et al. A formação de profissionais da saúde: aprendizagem significativa à luz da promoção da saúde. Cogitare Enfermagem, Curitiba, v. 12, n. 2, p. 236-240, 2007.

COLOMBO, A. A.; BERBEL, N. A. N. A Metodologia da Problematizaçáo com o Arco de Maguerez e sua relação com os saberes de professores. Semina: Ciências Sociais e Humanas, Londrina, v. 28, n. 2, p. 121-146, 2007.

CONSELHO FEDERAL DE FISIOTERAPIA E TERAPIA OCUPACIONAL - COFFITO. Formação profissional. Disponível em: <http://coffito.org.br/conteudo/ con_view.asp?secao=49>. Acesso em: 15 jan. 2010.

CYRINO, E. G.; TORALLES-PEREIRA, M. L. Trabalhando com estratégias de ensino-aprendizado por descoberta na área da saúde: a problematização e a aprendizagem baseada em problemas. Cadernos de Saúde Pública, Rio de Janeiro, v. 20, n. 3, p. 780-788, 2004. http://dx.doi.org/10.1590/S0102-311X2004000300015

DEMO, P. Professor do futuro e reconstrução do conhecimento. Petrópolis: Vozes, 2004.

FAGUNDES, N. C.; FRÓES BURNHAM, T. Discutindo a relação entre espaço e aprendizagem na formaçáo de profissionais de saúde. Interface: Comunicação, Saúde, Educação, Botucatu, v. 9, n. 16, p. 105-14, 2005. http:// dx.doi.org/10.1590/S1414-32832005000100009

FEUERWERKER, L. C. M. Reflexões sobre experiências de mudança na formação de profissionais de saúde. Olho Mágico, Londrina, v. 10, n. 3, p. 21-26, 2003.

FEUERWERKER, L. C. M.; SENA, R. R. Contribuiçăo ao movimento de mudança na formaçáo profissional em saúde: uma avaliação das experiências UNI. Interface: Comunicação, Saúde, Educação, Botucatu, v. 6, n. 10, p. 37-50, 2002. http://dx.doi.org/10.1590/ S1414-32832002000100004

FREIRE P. Pedagogia do oprimido. 38. ed. Rio de Janeiro: Paz e Terra, 2004.

FREIRE P. Educação como prática da liberdade. 30. ed. Rio de Janeiro: Paz e Terra, 2007.

GALDEANO, L. E.; ROSSI, L. A.; ZAGO, M. M. F. Roteiro instrucional para a elaboração de um estudo de caso clínico. Revista Latino-Americana de Enfermagem, Ribeirão Preto, v. 11, n. 3, p. 371-375, 2003. http://dx.doi. org/10.1590/S0104-11692003000300016

GUANAES, C.; MATTOS, A. T. R. O Grupo de Reflexão na formação do profissional de saúde: um enfoque construcionista social. Gerais: Revista Interinstitucional de Psicologia, Juiz de Fora, v. 1, n. 1, 79-85, 2008. 
KODJAOGLANIAN, V. L. et al. Inovando métodos de ensino-aprendizagem na formação do psicólogo. Psicologia: Ciência e Profissão, Brasília, v. 23, n. 1, p. 2-11, 2003. http://dx.doi.org/10.1590/S1414-98932003000100002

KOMATSU, R. S. et al. Guia do processo de ensinoaprendizagem "aprender a aprender". 4. ed. Marília: Faculdade de Medicina de Marília, 2003.

MACHADO, M. F. A. S. et al. Integralidade, formação de saúde, educação em saúde e as propostas do SUS: uma revisão conceitual. Ciência \& Saúde Coletiva, Rio de Janeiro, v. 12, n. 2, p. 335-342, 2007. http://dx.doi. org/10.1590/S1413-81232007000200009

MAGUEREZ, C. Elementos para uma pedagogia de massa na assistência técnica agrícola: relatório. Campinas: Coordenadoria de Assistência Técnica Integral da Secretaria da Agricultora do Estado de São Paulo, 1970.

MARIN, M. J. S. et al. Aspectos das fortalezas e fragilidades no uso das metodologias ativas de aprendizagem. Revista Brasileira de Educação Médica, Rio de Janeiro, v. 34, n. 1, p. 13-20, 2010. http://dx.doi. org/10.1590/S0100-55022010000100003

MITRE, S. M. et al. Metodologias ativas de ensinoaprendizagem na formação profissional em saúde: debates atuais. Ciência \& Saúde Coletiva, Rio de Janeiro, v. 13, p. 2133-2144, 2008. Suplemeto 2. http://dx.doi. org/10.1590/S1413-81232008000900018

MORAES, K. C.; BERBEL, N. A. N. O uso da metodologia da problematização para a investigação sobre avaliação da aprendizagem. O que há de específico para o ensino superior? Semina: Ciências Sociais e Humanas, Londrina, v. 27, n. 2, p. 169-186, 2006.

PENAFORTE, J. John Dewey e as raízes filosóficas da aprendizagem baseada em problemas. In: MAMEDE, S. et al. (Org.). Aprendizagem baseada em problemas: anatomia de uma nova abordagem educacional. Fortaleza: Escola de Saúde Pública; São Paulo: Hucitec, 2001. p. 49-78.

TOLDRÁ, R. C.; CARVALHO, F. B.; BALLARIN, M. L. G. S. Trinta anos de história da Faculdade de Terapia Ocupacional da PUC-Campinas: um trabalho de rememoração. Revista de Terapia Ocupacional da USP, São Paulo, v. 19, n. 2, p. 131-136, 2008. http://dx.doi. org/10.11606/issn.2238-6149.v19i2p131-136

TOLDRÁ, R. C.; PALM, R. C. M. Programa de aprimoramento profissional em terapia ocupacional da PUC-Campinas. Revista de Ciências Médicas, Campinas, v. 18 , n. 3, p. 131-141, 2009.

\section{Contribuição dos Autores}

Maria Luisa Gazabim Simões Ballarin responsável pela concepção do trabalho, coleta e análise de dados, organização do conteúdo, discussão e redação do texto. Rosibeth Del Carmen Muñoz Palm, Fábio Bruno de Carvalho, Rosé Colom Toldrá foram responsáveis pela análise, discussão e revisão do texto. 